\title{
STUDENTS PERSPECTIVE REGARDING ONLINE EDUCATION DURING 2019 PANDEMIC: A CASE STUDY ON THE PUBLIC UNIVERSITIES OF KARACHI
}

\author{
Zaeema Asrar Mohiuddin \\ Assistant Professor, \\ Department of Commerce, University of Karachi, \\ Sindh, Pakistan \\ Email: zasrar@uok.edu.pk

\section{Haider Iqbal} \\ Research Scholar, \\ Department of Commerce, University of Karachi, \\ Sindh, Pakistan \\ Email: haideriqbal.hi@gmail.com
}

\begin{abstract}
Online education is recognized and well-known method of learning in the developed countries, however, it is becoming popular in the developing countries like Pakistan. Coronavirus Disease 2019 was officially acknowledged as pandemic on March 11, 2020 by the World Health Organization. Beyond other sectors, education sector has also been affected significantly because of the pandemic. The situation tested the readiness of universities to deal with the crisis. This study is conducted to have the students' view point regarding online education during Coronavirus Disease 2019 pandemic. Total 300 students of University of Karachi and Federal Urdu University participated in the research. Pre-designed questionnaire is used for the purpose of data analysis. Software used include SPSS and MS-Excel as both the software are easy to use and have user friendly interface. Results reveal that Recorded lectures are the most preferred mode of online learning. Most of the students are with the view point that electricity breakdown is the major technical issue faced during online learning. Moreover, communication gap between instructor and student is the major nontechnical issue faced during online learning. Traditional/ offline Education have been the most preferred mode of learning in usual circumstances.
\end{abstract}

\section{KEYWORDS}

Coronavirus Disease 2019, Pandemic, Universities, Online Education, Pakistan 


\section{INTRODUCTION}

Web is a prominent advanced development revolutionizing the general public together with institutes in the world. Therefore, institutions should utilize the Internet for educating, and one dynamic development of this is the use of online approaches and methods. Online education is the learning relied or based on the internet for teacher/ student communication and distribution of learning material. In the last 2 decades online education has expanded swiftly in the world. Online education is quite common in developed economies; however, the format is comparatively new in the developing countries like Pakistan, India, Bangladesh etc. Virtual University is the pioneer institutes offering online education certifications and programs. A number of students across the country is learning the skills and gaining knowledge according to their convenience. A blend of advanced educational methods for lecture delivery is being utilized by the university. Majorly activity-based content is used by the university to promote active students' participation. Through the facility of Moderated Discussion Board (MDB) learning Management System (LMS) is hosted by Virtual University. Students are allowed to send their questions to the instructors via email. In addition, connection with private institutions constituting Private Virtual Campuses has also been established throughout the country. Students can interact in classrooms with a sense of belongingness due to the establishment of these campuses.

COVID-19 (Corona Virus Disease) 2019 pandemic was officially declared as pandemic on March 11, 2020 by the World Health Organization after thorough examination of the global circumstances. Before the pandemic, online education was not very much common in the developing economies like Pakistan. The pandemic increased its significance drastically. Educational institutes were closed due to the pandemic throughout the world. The situation was indeed a test of the universities' readiness to deal with the crisis that demands advanced experts and IT infrastructure. Different universities formulated different strategies to provide online education to their students in suitable manner. Various platforms and methods employed by the universities for the delivery of online education includes; Google classroom, Google meet, Microsoft Teams etc. Besides, teachers also used WhatsApp, Facebook etc. as the part of online education strategy mainly because of the fact that these platforms are very common among young generation. The strategy greatly facilitated both teachers and students and reduced communication gap up to the great extent. Other frequently used video conferencing solutions include WebEx, Skype for business, Zoom etc.

There was the time when universities/ institutes offering online education used to be perceived of lesser quality and validity as compare to the universities offering different degree and certification programs using traditional formats and approaches. However, the pandemic has transformed the mindset and perception towards the online education and it is being considered and given due status throughout the world and particularly 
in developing countries. As any other format of education delivery, online education also has both positives and negatives. On one side it is a flexible arrangement of learning but on the other side lack of classroom environment is a matter of apprehension. Nevertheless, such problems can be overcome by using appropriate approaches.

The research is conducted in order to have the students' opinion regarding the online education during COVID-19 pandemic. Specific research objectives are to identify the preferred mode of online learning, major technical issue faced during online learning, major non-technical issue faced during online learning, preferred mode of learning in usual circumstances i.e. in the absence of pandemic and the suitability of launching online degree and certification programs. This study is necessary to provide solid basis of decision making for the public sector universities, particularly the discussed ones, in the rapidly changing global as well as local scenario.

The descriptive study is based on the primary data collected from the students of two major general universities of Karachi namely, University of Karachi and Federal Urdu University of Arts, Science and Technology. Both the universities have numerous faculties, for the purpose of this study faculties of management and administrative sciences are selected. Total 300 hundred students (approximately 50 students from each strata/ department) participated in the research. Moreover, suitable descriptive statistical methods are applied for the purpose of data analysis. Software used for the data management and analysis are SPSS and MS-Excel. Major contribution in the study is of females, the age group between 23-27, answered the most; furthermore, majority of the students are from bachelors' study programs. Results of the study reveal that recorded lectures are the students' preference rather than the live interaction. Most of the students are with the view point that electricity breakdown is the major technical issue faced during online learning. Major non-technical issue being faced by the students is the communication gap between instructor and student. Traditional education has been the most preferred mode of learning in normal circumstances. Furthermore, it is also identified that launching virtual certification programs is a good option for the universities.

Pakistan is observing good and bad perspectives in acceptance and usage of information communication technology for learning purposes because there are numerous societal, political, cultural, psychological and technical restraints which are hindering the implementation of this advanced method generally in developing counties and specifically in Pakistan; moreover, instructors, students and developers perceive it differently because of diverse contextual circumstances which play a noteworthy part in success or failure of information and communication technology usage in delivering online education (Kundi, Nawaz, \& Khan, 2010). 
It is recommended in the research that both the online education delivery methods i.e. recorded lectures and live interactive sessions should become the part of online education. Ratio of both the strategies should be decided with the mutual consent of students and teachers. Moreover, the universities should also consider the option of launching virtual certification programs as it will be helpful in generating extra income as well as positively contribute towards the brand recognition in the country as well as beyond the borders.

\section{LITERATURE REVIEW}

Literature is from different sources including research journals and periodicals discussing online education as a separate head and in relation with COVID-19 Pandemic. Major topics reviewed comprise; concept of online education, significance of online education in the world, brief comparison of online education in developing and developed economies, situation of online education before and after COVID-19 pandemic, issues faced to the different parties (students, teachers, management etc.) in the delivery of online education and situation of online education before and after the pandemic in the country. Review of the related literature greatly facilitates to understand the issue in an efficient manner.

Web is a notable state-of-the-art progress reforming the general public along with institutions across the world. In light of this, institutions should utilize the Internet for educating, and one dynamic development of this is the use of online approaches and methods (Akhter \& Mahmood, 2018). Online education can simply be defined as the learning which is based or relied on the internet for student / teacher communication and dissemination of study materials. Online education has expanded rapidly in the last 2 decades across the world (Hart, Berger, Jacob, Loeb, \& Hill, 2019). This mode of education is recognized and well-known method of learning in the developed countries, however, it is becoming popular in the developing countries like Pakistan, India, Bangladesh etc. Online education provides various certifications and degree programs from K-12 to higher education level (Hussain, 2012).

The incorporation of e-learning plans into the educational arrangement has reformed the process of attainment and distribution of knowledge through the world. Though numbers of investigators favor the usefulness of e-learning incorporation in terms of the modernization it offers to involve with students does not assurance the success of e-learning programs. This can be observed in developing countries like Pakistan, which have not yet been able to benefit completely from the rewards of e-learning (Qureshi, Ilyas, Yasmin, \& Whitty, 2012).

Teachers have different perspectives when it comes to online education, on the basis of their perceptions, teachers are divided into three different classes which include; 
Cynics, Moderates and Adaptors. Cynics have negative opinion regarding online education; however, they have sound pedagogical beliefs, they are not willing to adapt with the varying circumstances. Moderates like information and communication technology and are ready to adapt to new educational methods with some training and supervision. Adaptors are the intelligent leaders who use e-Learning for personal development and external improvements by continuously revolutionizing their teaching with the state-of-the-art technologies. As a matter of fact, all the three kinds can be seen in Pakistan with varying ratio (Kundi, Nawaz, \& Khan, 2010).

In Pakistan, Virtual University is one of the leaders in introducing online education. The university was founded in 2002, it is offering various degree and certification programs. It is enabling the students for challenging jobs by offering advanced and skill-based programs. Virtual University of Pakistan utilizes a blend of advanced educational ways for instructional delivery to bring about economic as well as social betterment in Pakistan. Internet is the basis of instructional set-up of the university. Virtual Television Network along with Internet Technology is bridging-up the distance between the university, educators and the learners. Activity based contents are used by the educators of Virtual University to promote the active involvement of the learners. Learning Management System (LMS) is hosted by the university through the facility of Moderated Discussion Board (MDB). Students can also send the queries through email to the teachers. Besides, connection with private institutes constituting Private Virtual Campuses has also been established across the country. The campuses serve the students in a way that they can interact in classrooms with a sense of belongingness (Hussain, 2012).

COVID-19 was officially declared as pandemic on March 11, 2020 by the World Health Organization after thorough examination of the global circumstances. Beyond other sectors, education sector has also been affected significantly due to the pandemic (Guide2Research, 2020). COVID-19 spread led to the closure of educational institutes across the world. The situation tested the readiness of universities to deal with a crisis that necessitates the support of advanced expertise comprising hardware and software to enable effective online education. This closure enhanced the expansion of online education in order to continue the learning. Universities across the world formulated strategies to deliver the courses in appropriate manner and to evaluate the students' performance. Universities started investing in setting up the online educational infrastructure according to their capacities. Universities in Pakistan are utilizing Google meet, Microsoft Teams, Edmodo and Moodle as learning management systems accompanied by their applications for video conferencing. Other frequently used video conferencing solutions comprise Skype for business, Zoom, and WebEx etc. (Mukhtar, Javed, Arooj, \& Sethi, 2020). 
Universities offering online education used to be perceived of lesser validity and quality as compare to the universities offering programs in traditional settings. However, the pandemic has changed the dynamics and all the institutes are considering the significance of online education. Various articles have been published addressing different facets of online education in the current year. Private sector universities are the advocate of online education and they have swiftly switched their strategy from traditional setup to the online format. However, students have been resistant to online education. They claim that infrastructure, access to technology and connectivity are not set up to justifiably meet the needs of students in Pakistan. It is being argued by the researchers and academicians that universities in Pakistan are actually doing Emergency Remote Learning (ERT) rather than e-learning during the pandemic of COVID-19. ERT is temporary or short-term switch of education because of the crisis with not appropriate change in pedagogy, however, online education demands careful and deliberation. Faculty have been struggling to make a shift from traditional setting to the online format of education without much preparedness. Majority of the teachers have not delivered online lectures before this situation and trying various approaches to appropriately deliver the course (Dossa, Lakhani, \& Hussain, 2020).

As any other format of learning, online education also has both advantages and disadvantages. One of the key advantages of the format is that it is a flexible learning arrangement. It is convenient in distant learning and during COVID 19 condition it facilitates a lot in continuing the education. Teacher has the authority to unmute the mics, videos. Moreover, teachers can ascertain whether students are listening carefully or not. Students who are not confident may approach the teachers via different platforms e.g. WhatsApp easily. Another advantage of this format is that it enables student-centered education. Students can listen the lecture easily according to their convenience and can learn. Online education is enhancing the self-learning skills of the students as well. Recordings of the lectures help the students to revise the concepts easily. One of the major limitations of online education is that it is not suitable for hands on training. Due to the absence of class room environment, students loose concentration on lecture. A number of students do not have appropriate gadgets for the online education. Another limitation is the maintenance of proper discipling during the lectures, variety of disciplinary issues have been noted in various universities. Furthermore, assessment is also a challenging task in this format (Mukhtar, Javed, Arooj, \& Sethi, 2020).

Literature reveals that online education is basically learning based on the internet for student/ teacher communication and dissemination of study materials. Virtual University, founded in 2002, is one of the leaders in introducing online education in Pakistan. It is offering various degree and certification programs. 
COVID-19 was officially declared as pandemic on March 11, 2020 by the World Health Organization after detailed inspection of the global conditions. Beside other sectors, education sector has also been affected significantly because of the pandemic. Universities offering online education used to be perceived of lesser validity and quality as compare to the universities offering programs in traditional settings. However, the pandemic has changed the mindset and perception towards the online education and it is being considered and given due importance across the world and specifically in developing economies.

As any other format of learning, online education also has both advantages and disadvantages. On one hand it is a flexible form of learning but on the other hand lack of classroom environment is a matter of concern. However, such issues can be overcome by employing suitable strategies by teachers and the management.

\section{RESEARCH OBJECTIVES}

1. To identify the preferred mode of online learning

2. To find the major technical issue faced during online learning

3. To uncover the major non-technical issue faced during online learning

4. To highlight the preferred mode of learning in usual circumstances i.e. in the absence of pandemic

5. To identify the suitability of launching online degree and certification programs

\section{RESEARCH METHODOLOGY}

The descriptive study was based on the primary data collected from the students of two major general universities of Karachi namely, University of Karachi and Federal Urdu University of Arts, Science and Technology. Both the universities have various faculties, for the purpose of this study faculties of management and administrative sciences were selected based on the researchers' interest and convenience.

Three different departments of Faculty of Management and Administrative Sciences (University of Karachi) includes Department of Commerce, Department of Public Administration and Karachi University Business School. Department of Commerce, Business Administration and Economics comprise the faculty of management and administrative sciences of Federal Urdu University. Students from mentioned six strata were approached and pre-designed questionnaire was used for the purpose of data collection. Total 300 hundred students (approximately 50 students from each strata/ department) participated in the research. Response rate is approximately $90 \%$ in all the questions. Moreover, suitable descriptive statistical methods were applied for the purpose of data analysis. Software used for the data management and analysis are SPSS and MS-Excel. Both the brands are easy to use and have user friendly interface. 


\section{RESEARCH FINDINGS AND DISCUSSIONS}

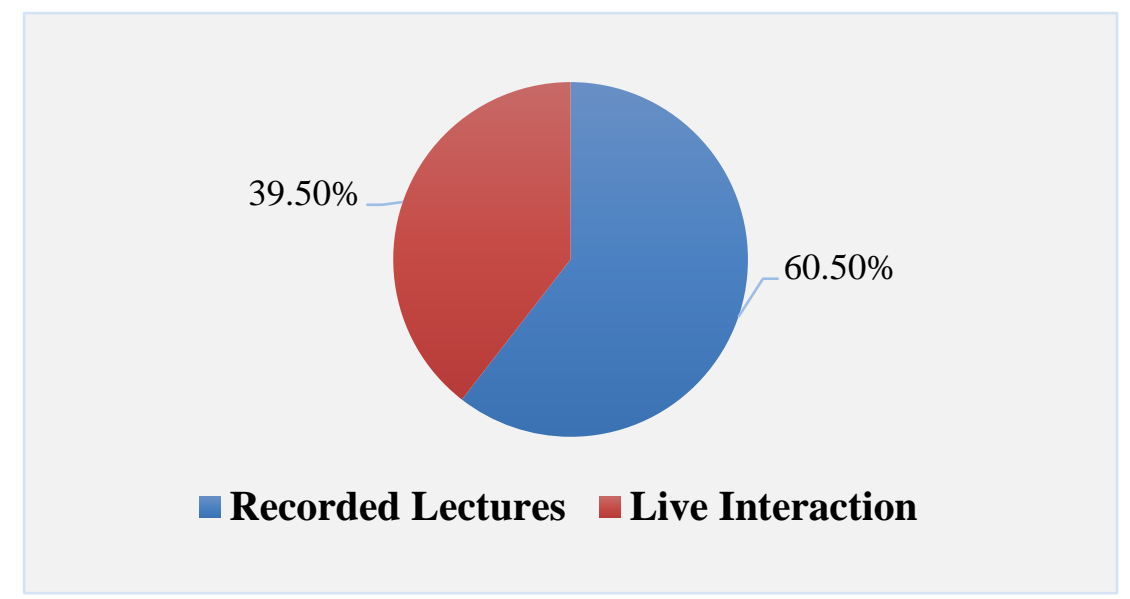

Figure-1 represents the students' preference regarding online learning method.

Approximately $60 \%$ of the students are inclined towards recorded lectures; while, about $40 \%$ choose live interactive sessions. Value 1 was assigned to the option of recorded lectures in SPSS and value 2 was given to live interactions, mode value (most repeated value) is found 1 which represents recorded lectures.

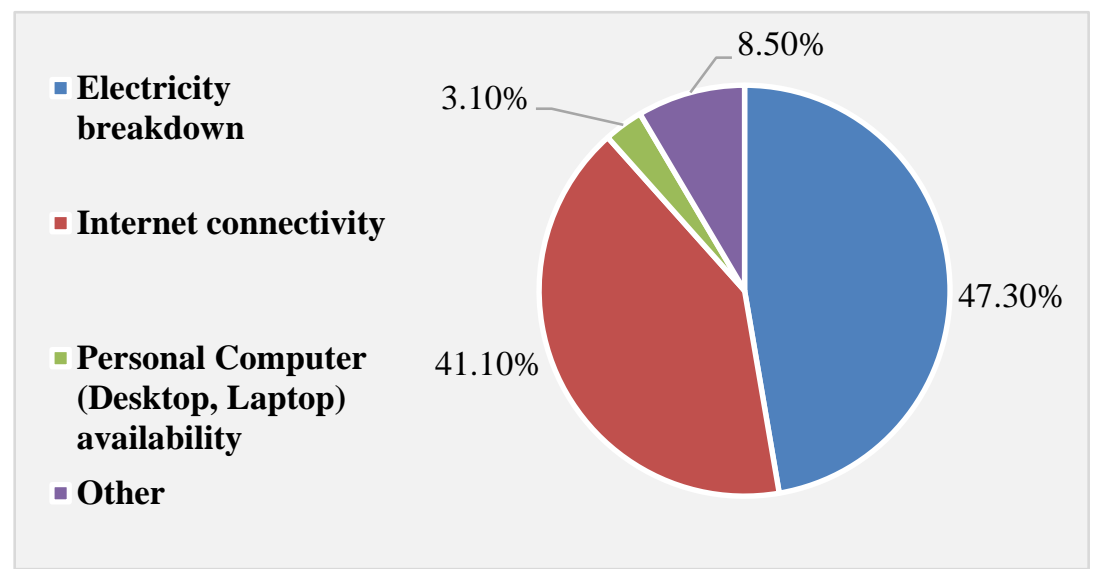

Figure-2 reveals major technical issue faced by the students during online learning.

Around $47 \%$ of the students find electricity breakdown as the major technical issue, approximately $41 \%$ consider internet connectivity as the major issue. Mode value is found 2 which was assigned to the option of electricity breakdown. Major nontechnical issue faced by approximately $45 \%$ of the students during online learning is 
communication gap between themselves and their respective instructors.

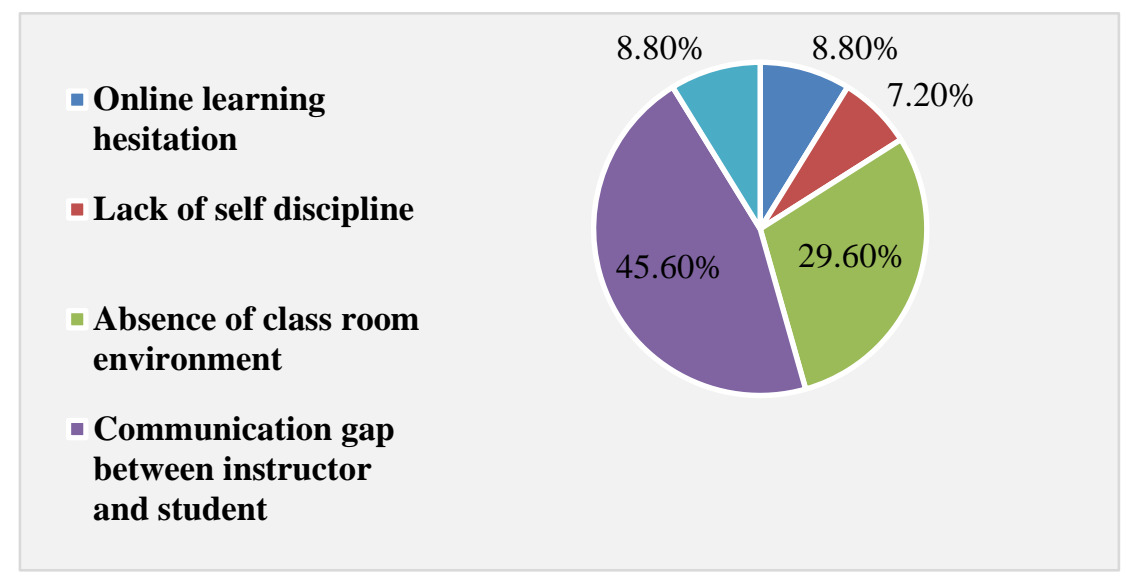

Figure-3 Major Non-Technical Issue Faced During Online Learning

Figure-3 reveals, mode value is found 4 which represents the same issue. $30 \%$ of the students considers absence of classroom environment as the major non-technical issue.

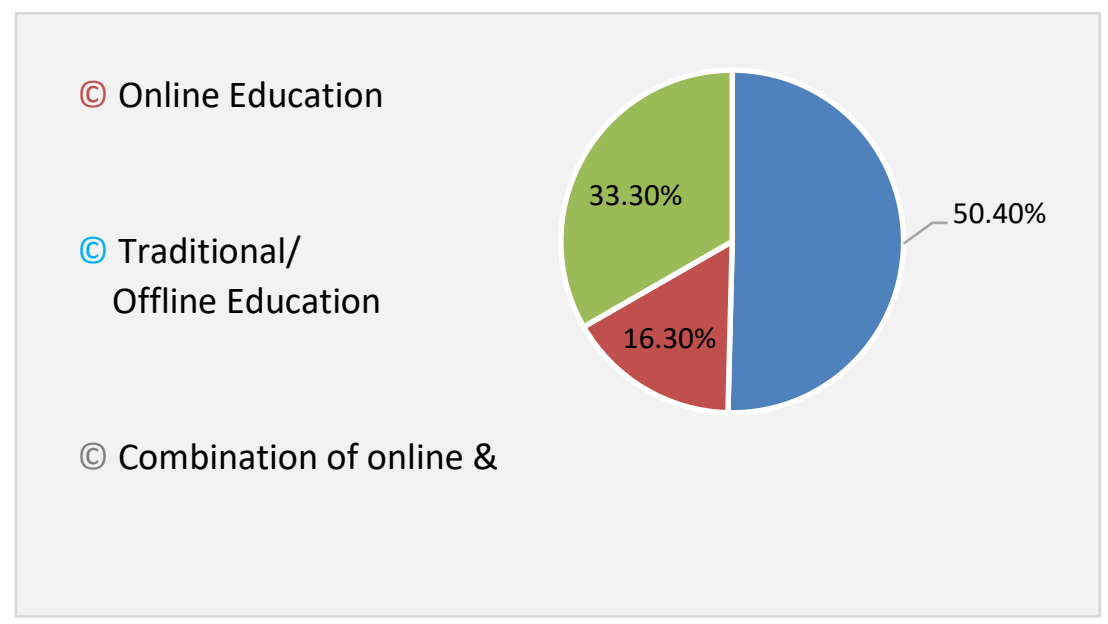

Figure-4 Preferred mode of learning in usual circumstances

Mode value is found 2 which represents traditional/ offline education. Around 50\% of the students will prefer traditional learning format in usual circumstanced i.e. in the absence of any sort of pandemic or emergency. Around 30\% of the students consider that combination of online and traditional education formats will be suitable in usual situation, figure- 4 discloses. 
Table-1

Gender of the Respondents

Gender

Female $\quad 65.1 \%$

Table-1 reveals that around $65 \%$ of the participants were females. Ages of the participants were between 18-27.

Table-2

Age of the Respondents

\begin{tabular}{cc}
\multicolumn{2}{c}{ Age } \\
\hline $18-22$ & $39.5 \%$ \\
$23-27$ & $60.5 \%$ \\
$28-32$ & $00.0 \%$ \\
$33-37$ & $00.0 \%$ \\
$38-42$ & $00.0 \%$ \\
Above 42 & $00.0 \%$ \\
\hline
\end{tabular}

Table-2 enrolled in either bachelors (around 65\%) or masters programs

Table-3

Study Program of the Respondents

\begin{tabular}{cc}
\hline \multicolumn{2}{c}{ Study Program } \\
\hline Bachelors & $64.60 \%$ \\
Masters & $35.40 \%$ \\
M.Phil. & $00.00 \%$ \\
Ph.D. & $00.00 \%$ \\
\hline
\end{tabular}

(Table-3). Shows the study program at which majority is from Bachelors program.

Table-4

Opinion of the students regarding virtual degree programs launching

\begin{tabular}{lccc}
\hline \multicolumn{4}{c}{ Launching virtual / online degree programs } \\
\hline & $\mathrm{x}$ & $\mathrm{f}$ (converted into percentage) & $\mathrm{fx}$ \\
Very Good Option & -2 & 11.6 & -23.2 \\
Good Option & -1 & 18.6 & -18.6 \\
Average Option & 0 & 31.8 & 0 \\
\hline
\end{tabular}




\begin{tabular}{llcl} 
Bad Option & 1 & 20.9 & 20.9 \\
Very Bad Option & 2 & 17.1 & 34.2 \\
Total & & 100 & 13.3 \\
\hline
\end{tabular}

Mean value is found 0.133 , which is close to 'average option'. It is recommended to conduct a separate research for this particular case.

Table-5

Opinion of the students regarding virtual certification programs launching

\begin{tabular}{lccc}
\multicolumn{4}{c}{ Launching virtual/ online certification programs } \\
& $\mathbf{X}$ & $\mathbf{f}$ (converted into percentage) & $\mathbf{f x}$ \\
\cline { 3 - 4 } Very Good Option & -2 & 30 & -60 \\
Good Option & -1 & 27.7 & -27.7 \\
Average Option & 0 & 34.6 & 0 \\
Bad Option & 1 & 7.7 & 7.7 \\
Very Bad Option & 2 & 0 & 0 \\
Total & & 100 & -80 \\
\hline
\end{tabular}

Mean value is -0.8 which reveals that it's a good option for the discussed universities to launch virtual/ online certification programs.

Major participation in the study is of females, the age group between 23-27 responded the most; moreover, majority of the students are from bachelors' study programs.

Findings of the study disclose that recorded lectures are the students' preference rather than the live interaction. Most of the students are with the view point that electricity breakdown is the major technical issue faced during online learning. Major nontechnical issue being faced by the students is the communication gap between instructor and student. Traditional/ offline Education have been the most preferred mode of learning in usual circumstances. Furthermore, it is a good option for the universities to launch virtual certification programs.

Major limitation of the study is that only descriptive statistical techniques are applied for the purpose of data analysis. Limitation of descriptive statistical techniques is that the results extracted by applying such techniques cannot be diverted to the entire population. However, proper stratification in the sampling and appropriate sample size (300) is expected to cover this limitation up to the considerable extent. The major reason behind opting the descriptive statistical methods is that these methods are easily interpretable as well as understandable, thus, it will help the decision makers of the public sector universities of Pakistan in general and discussed universities in particular 
to comprehend the situation in an easy and time efficient manner. Furthermore, the literature reviewed is also limited due to the infancy nature of the issue online education during COVID-19 pandemic.

\section{RECOMMENDATIONS}

Recorded lectures have been the preference of the most of the students. Electricity breakdown and internet connectivity are the two major non-technical issues faced by the students during online learning. Two appearing reasons behind this preference is the electricity break-down and internet connectivity issues. Recorded lectures can be listened by the students according to their convenience, however, proper online learning management systems are required to ensure whether students are listening the lectures or not. On the other hand, live interaction is the preference of about $40 \%$ students. As a matter of fact, live interaction with the teachers help the students to understand the topic in a better way. In short, both the formats have their own perks and costs. It is better to use both the strategies with varying percentage according to the suitability of students and teachers. It is good to reach the desired ratio of the strategies with the common consent of both the parties.

Teachers have different opinions when it comes to online education and can be classified into three different categories; Cynics, Moderates and Adaptors. Adaptors have very positive attitude towards new teaching methods. Thus, strategies should be formulated by the universities to change the mindset of other two categories. This conversion will surely be very helpful for the online education system.

Students are with the view point that the universities should offer virtual certification programs. As a matter of fact, launching of virtual certification programs will be helpful for the universities in various ways. Most importantly, the programs will help the universities in generating extra income. It will be beneficial for the faculty as well because it will help the teachers to utilize their extra time and deliver quality education to those who cannot travel to the respective universities. Finally, such certification programs will help in establishing the infrastructure necessary for delivering fullfledged degree programs. It is an opportunity for both the public sector universities to strengthen the financial position as well as to get recognition beyond the borders.

\section{REFERENCES}

Akhter, H., \& Mahmood, D. M. (2018). Study of the Impact of Online Education on Student's learning at University. International Journal of Distance education and E-learning, $3(2)$.

Dossa, S., Lakhani, R. T., \& Hussain, H. (2020, May 29). The future of online higher education

in Pakistan. Retrieved from The Express Tribune:


https://tribune.com.pk/article/96452/from-emergency-to-perseverance-in-onlinehigher-education

Guide2Research. (2020, June 30). 50 Online Education Statistics: 2020 Data on Higher Learning \& Corporate Training. Retrieved from Guide2Research: http://www.guide2research.com/research/online-education-statistics

Hart, C. M., Berger, D., Jacob, B., Loeb, S., \& Hill, M. (2019). Online Learning, Offline Outcomes: Online Course Taking. AERA Open, 5(1), 1-17.

Hussain, D. I. (2012). STUDY ON INSTRUCTIONAL PARADIGMS OF VIRTUAL EDUCATION IN PAKISTAN: A LEARNERS' PERSPECTIVE. The Turkish Online Journal of Educational Technology, 11(2), 178-186.

Kundi, G. M., Nawaz, A., \& Khan, S. (2010). THE PREDICTORS OF SUCCESS FOR ELEARNING IN HIGHER EDUCATION INSTITUTIONS (HEIs) IN N-W.F.P, PAKISTAN. Journal of Information Systems and Technology Management, 7(3), 545578.

Mishra, L., Gupta, T., \& Shree, A. (2020). Online teaching-learning in higher education during lockdown period of COVID-19 pandemic. International Journal of Educational Research Open. Retrieved from https://doi.org/10.1016/j.ijedro.2020.100012

Mukhtar, K., Javed, K., Arooj, M., \& Sethi, A. (2020). Advantages, Limitations and Recommendations for online learning during COVID-19 pandemic era. Pakistan Journal of Medical Sciences, 36.

Qureshi, I. A., Ilyas, K., Yasmin, R., \& Whitty, M. (2012). Challenges of implementing elearning in a Pakistani university. Knowledge Management \& E-Learning: An International Journal, 4(3), 310-324.

Radha, R., Mahalakshmi, K., Kumar, D. V., \& Saravanakumar, D. A. (2020). E-Learning during Lockdown of Covid-19 Pandemic: A Global Perspective. International Journal of Control and Automation, 13(4), 1088-1099. 